\title{
After bariatric surgery, do superficial fat and deep fat decrease differently?
}

Ryeolwoo Kim ${ }^{1}$, Youngsung Suh ${ }^{2}$, Seungwan Ryu ${ }^{3}$, Mikyung Kim ${ }^{4}$, Daegu Son ${ }^{1}$

Departments of ${ }^{1}$ Plastic and Reconstructive Surgery, ${ }^{2}$ Family Medicine, ${ }^{3}$ Surgery, and ${ }^{4}$ Internal Medicine, Keimyung University School of Medicine, Daegu, Korea
This article was presented at the PRS Korea 2017 meeting on December 10, 2017, in Seoul, Korea.
Background With the increasing frequency of body contouring surgery following weight loss, plastic surgeons have paid considerable attention to subcutaneous fat. However, few studies have investigated superficial and deep fat changes after bariatric surgery, and such studies have been limited to macroscopic assessments. The purpose of this study was to evaluate changes in superficial and deep fat in bariatric surgery patients using computed tomography (CT) to obtain quantitative measurements.

Methods This study included 11 patients (five males, six females; average age, 27 years) who underwent bariatric surgery at Dongsan Medical Center from October 2013 to October 2016. We excluded patients with a body mass index (BMI) $<30 \mathrm{~kg} / \mathrm{m}^{2}$ and those without both preoperative and postoperative CT images. We analyzed changes in subcutaneous fat area on CT images, with a mean follow-up of 5.5 months. We also performed a subgroup analysis using a BMI cutoff of $40 \mathrm{~kg} / \mathrm{m}^{2}$.

Results Patients undergoing bariatric surgery showed significant reductions in weight, total fat, and the area of superficial and deep fat $(\mathrm{P}=0.002)$. In patients with a BMI less than $40 \mathrm{~kg} / \mathrm{m}^{2}$, the reduction rate of superficial subcutaneous adipose tissue (sSAT) tended to be higher than that of deep subcutaneous adipose tissue (dSAT). Conversely, in patients with a BMI over $40 \mathrm{~kg} / \mathrm{m}^{2}$, the reduction rate of dSAT was higher than that of sSAT.

Conclusions We observed a difference in the reduction rate of SSAT and dSAT during weight loss after bariatric surgery, although it was not statistically significant. The reduction rates differed according to BMI.

Keywords Subcutaneous adipose tissue / Bariatric surgery / Weight loss / Metabolic syndrome

\section{INTRODUCTION}

Bariatric surgery has recently become popular for treatment of morbidly obese patients, and post-bariatric body contouring surgery has also become more common. Post-bariatric body contour-

Received: May 30, 2020 Revised: Jul 13, 2020 Accepted: Jul 21, 2020 Correspondence: Daegu Son Department of Plastic and Reconstructive Surgery, Institute for Medical Science, Keimyung University School of Medicine, 1095 Dalgubeol-daero, Dalseo-gu, Daegu 42601, Korea Tel: +82-53-258-7817, Fax: +82-53-258-4590, E-mail: handson@dsmc.or.kr

Copyright @ 2020 The Korean Society for Aesthetic Plastic Surgery.

This is an Open Access article distributed under the terms of the Creative Commons Attribution Non-Commercial License (https://creativecommons.org/licenses/by-nc/4.0/) which permits unrestricted non-commercial use, distribution, and reproduction in any medium, provided the original work is properly cited. $\quad$ www.e-aaps.org ing surgery, from conventional abdominoplasty to lower- and upper-limb contouring, focuses on reducing redundant tissues and reshaping the body. Most body contouring procedures are performed due to a decreased volume of subcutaneous fat and increased skin laxity after massive weight loss. The abdominal area is the most common area for body contouring surgery in massive weight loss patients; therefore, our study focused on abdominal subcutaneous adipose tissue (SAT).

Adipose tissue is an active endocrine and immune organ. In an obese state, adipocyte metabolism is impaired and cell homeostasis is broken $[1,2]$. For this reason, obesity is considered to be an independent risk factor for mortality and a causative factor of several major diseases, including coronary heart disease, hypertension, and various metabolic diseases [3]. Current treatments for obesity range from dietary modifications to surgical treatment. 
Subcutaneous fat tissue is divided into a superficial fat layer and a deep fat layer by the superficial fascial system, and these two layers have different histological and molecular characteristics $[4,5]$. Histologically, the deep fat layer is looser, and has more fibrous septa. On a molecular level, functional differences with subsequent differences in gene expression have been noted between the two layers. According to previous studies, deep fat is more metabolically active than superficial fat and is associated with metabolic diseases, such as type 2 diabetes mellitus (T2DM) [6-10].

Bariatric surgery results in durable and stable weight loss within 1 year following surgery. It is also called "DM surgery," since it results in up to an $80 \%$ resolution of T2DM [11]. There are two procedural types: restrictive and malabsorptive. The combination of these two types, as in gastric bypass or Roux-en-Y gastric bypass (RYGB), is the most popular bariatric surgical procedure. These procedures do not involve direct manipulation of the SAT, but instead induce a negative caloric balance that reduces SAT indirectly.

Although many studies have investigated SAT, most have been done at a single time point, instead of using a longitudinal design. Moreover, few studies have compared the changes that occur between the two layers of fat tissue upon losing weight. Because it is difficult to consistently follow-up with individual patients, no suitable modality for evaluation has been established. Therefore, we focused on (1) bariatric surgery, as a dramatically effective method of losing weight, and (2) fat-setting computed tomography (fat $\mathrm{CT}$ ), as a quantitative measurement method to evaluate changes in superficial and deep fat. The aim of this study was to identify the changes in superficial fat and deep fat tissue measured by fat CT before and after bariatric surgery. The findings of this study will help achieve more desirable results from contouring surgery.

\section{METHODS}

\section{Patient selection}

The present prospective study covered a 3-year period between October 2013 and October 2016 (IRB 2018-01-01). The inclusion criterion were patients with a body mass index (BMI) of $30 \mathrm{~kg} / \mathrm{m}^{2}$ or higher, who underwent bariatric surgery at Dongsan Medical Center, and who underwent fat CT before and after surgery. Patients with a BMI less than $30 \mathrm{~kg} / \mathrm{m}^{2}$, who underwent any additional abdominal procedure preoperatively or postoperatively, were missing either preoperative or postoperative fat CT, or had poorquality images that could not be examined were excluded from the study. Finally, 11 patients were included in this study. Three bariatric surgical procedures were used-sleeve, sleeve with bypass, and RYGB - and were performed by a single general surgeon (SR). The sleeve technique was used in patients with a BMI lower than $40 \mathrm{~kg} /$ $\mathrm{m}^{2}$, the sleeve with bypass technique was used in patients with a BMI greater than $40 \mathrm{~kg} / \mathrm{m}^{2}$, and RYGB was used in one case of "super obesity" with an extremely high BMI over $50 \mathrm{~kg} / \mathrm{m}^{2}$. Each pro- cedure was performed according to the standard technique. The timing of the first follow-up that included postoperative CT ranged from 2 to 12 months.

\section{$\mathrm{CT}$ and measurements}

Abdominal CT scanning was performed using a 128-channel dual CT scanner (Siemens, Erlangen, Germany) with patients in the supine position. An axial scan was performed by setting the fat scale as -30 to -190 Hounsfield units (known as the "fat setting") and a slice thickness of $10 \mathrm{~mm}$. The reference point of the measurement was the umbilicus, which was depressed without the influence of the zone of adherence and was clearly visible in all patients. The axial section image that was closest to the midpoint of the umbilicus was selected. This one-cut image was measured by an expert, who drew four standard lines using a consistent technique. Line 1 was the baseline (outside the torso), line 2 was the superficial fascial layer, line 3 was the muscle fascia, and line 4 was the mesentery. The area representing the fat tissue within each boundary was obtained through the program included with the CT scanner, and the area of the superficial and deep fat layers was obtained by calculating differences in area between these compartments (Fig. 1).

\section{Statistical analysis}

The statistical analysis was performed using the $\mathrm{R}$ program (version 3.4.0; University of Auckland, New Zealand) and was designed to describe the variables of interest at a confidence level of $95 \%$ in two-sided tests. Statistical significance was determined at a

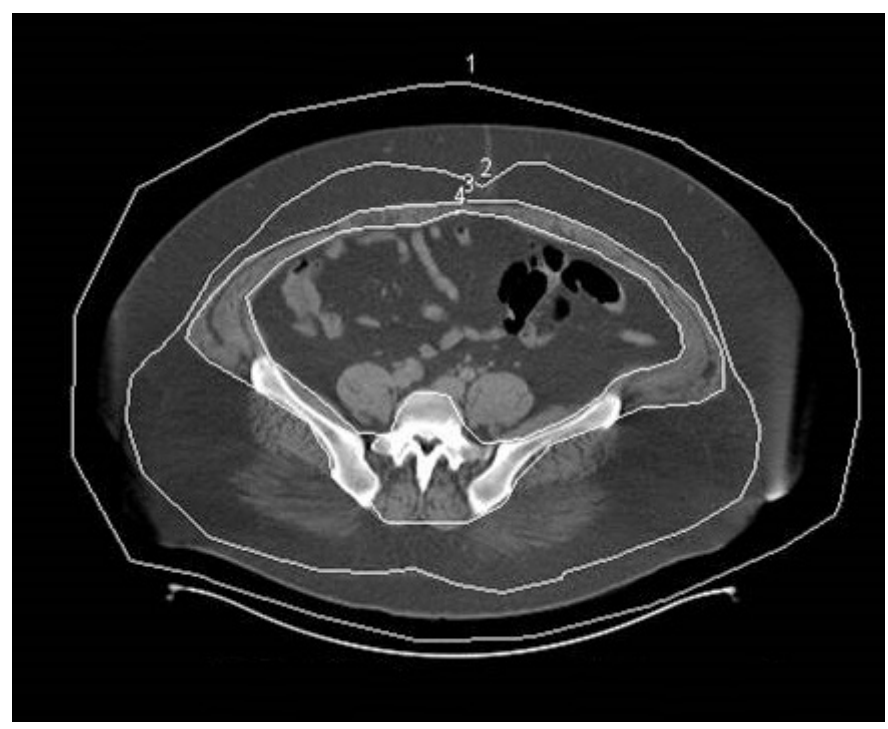

Fig. 1. How to calculate fat area on a computed tomography image. The fat area was calculated by differences of each line. 1 Area refers to the total body fat in the image, the difference in the area between lines 1 and 2 indicates the superficial fat area, the difference in the area between lines 2 and 3 corresponds to the area of deep fat, and the area between lines 3 and 4 denotes intramuscular fat deposition. 
level of $<0.05$ in two-sided tests. The Wilcoxon signed-rank test was performed to analyze differences in the fat area between the superficial and deep layers before and after bariatric surgery. Moreover, we analyzed whether there were differences between the two fat layers according to sex and BMI.

\section{RESULTS}

Eleven patients, with a mean age of 34.6 years (standard deviation [SD], 12.9 years) and a mean BMI of $41.8 \mathrm{~kg} / \mathrm{m}^{2}\left(\mathrm{SD}, 7.7 \mathrm{~kg} / \mathrm{m}^{2}\right)$ were followed up for a mean period of 5.5 months. Five patients underwent surgery using the sleeve procedure, five patients had a

Table 1. Patient demographics and surgical techniques

\begin{tabular}{lc}
\hline Characteristic & Value \\
\hline Mean age (yr) & 34.6 \\
Sex & 5 \\
Male & 6 \\
Female & \\
BMI (kg/m ${ }^{2}$ ) & 41.8 \\
Mean & 5 \\
$<40$ & 6 \\
$\geq 40$ & 5.5 \\
Mean follow-up period (mo) & \\
Bariatric surgery technique & 5 \\
Sleeve & 5 \\
Sleeve with bypass & 1 \\
Roux-en-Y & \\
\hline
\end{tabular}

$\mathrm{BMI}$, body mass index.

Table 2. Body weight and fat areas before and after surgery ( $n=11)$

\begin{tabular}{lccc}
\hline Variable & Preoperative & Postoperative & P-value \\
\hline Weight $(\mathrm{kg})$ & $118.3 \pm 28.3$ & $89.3 \pm 14.3$ & 0.002 \\
Total fat $\left(\mathrm{cm}^{2}\right)$ & $781.2 \pm 88.9$ & $502.3 \pm 190.7$ & 0.001 \\
Superficial fat $\left(\mathrm{cm}^{2}\right)$ & $295.3 \pm 99.0$ & $201.6 \pm 81.4$ & 0.002 \\
Deep fat $\left(\mathrm{cm}^{2}\right)$ & $257.8 \pm 101.5$ & $173.8 \pm 69.4$ & 0.002 \\
\hline
\end{tabular}

Values are presented as mean \pm SD.

${ }^{a}$ Wilcoxon signed-rank test.

Table 3. Reduction rate in superficial fat and deep fat ( $n=11)$

\begin{tabular}{lccc}
\hline Variable & Superficial fat & Deep fat & P-value $^{\text {al }}$ \\
\hline Preoperative & $295.3 \pm 99.0$ & $257.8 \pm 101.5$ & 0.278 \\
Postoperative & $201.6 \pm 81.4$ & $173.8 \pm 69.4$ & \\
Reduction rate & $29.1 \pm 24.3$ & $29.3 \pm 21.7$ & 1 \\
\hline
\end{tabular}

Values are presented as mean $\pm S D$. Reduction rate=(preoperative-postoperative)/preoperative $\times 100$.

${ }^{a}$ Wilcoxon signed-rank test. sleeve with bypass procedure, and one patient, with a BMI of 62.4 $\mathrm{kg} / \mathrm{m}^{2}$, underwent RYGB (Table 1 ).

After bariatric surgery, the patient's body weight and the areas of superficial and deep fat were significantly reduced compared to before surgery (Table 2). The superficial fat layer tended to occupy a larger area than the deep fat layer both preoperatively and postoperatively, although the difference was not statistically significant. There was also no significant difference in the reduction rate between the two areas (Table 3). We then conducted a subgroup analysis to examine whether there were differences due to the degree of obesity, comparing patients with a BMI less than $40 \mathrm{~kg} / \mathrm{m}^{2}$ to those with a BMI over $40 \mathrm{~kg} / \mathrm{m}^{2}$ (class III obesity, also known as extreme obesity). The statistical analysis of the patients with a BMI less than $40 \mathrm{~kg} / \mathrm{m}^{2}$ showed no significant decreases in body weight, superficial fat, or deep fat after surgery. In the patients with a BMI less than $40 \mathrm{~kg} / \mathrm{m}^{2}$, the reduction rate of superficial fat was higher than that of deep fat, but the difference was not statistically significant (Tables 4, 5). In patients with a BMI over $40 \mathrm{~kg} / \mathrm{m}^{2}$, there was

Table 4. Body weight and fat area before and after surgery in patients with a body mass index less than $40 \mathrm{~kg} / \mathrm{m}^{2}(\mathrm{n}=5)$

\begin{tabular}{lccc}
\hline Variable & Preoperative & Postoperative & P-value ${ }^{\text {a) }}$ \\
\hline Weight $(\mathrm{kg})$ & $97.4 \pm 12.2$ & $78.3 \pm 6.6$ & 0.063 \\
Total fat $\left(\mathrm{cm}^{2}\right)$ & $670.2 \pm 114.6$ & $436.6 \pm 43.4$ & 0.063 \\
Superficial fat $\left(\mathrm{cm}^{2}\right)$ & $230.0 \pm 50.5$ & $170.0 \pm 68.3$ & 0.125 \\
Deep fat $\left(\mathrm{cm}^{2}\right)$ & $193.6 \pm 42.6$ & $147.3 \pm 22.6$ & 0.125 \\
\hline
\end{tabular}

Values are presented as mean \pm SD.

${ }^{\text {al } W i l c o x o n ~ s i g n e d-r a n k ~ t e s t . ~}$

Table 5. Reduction rate in superficial fat and deep fat in patients with a body mass index less than $40 \mathrm{~kg} / \mathrm{m}^{2}(\mathrm{n}=5)$

\begin{tabular}{lccc}
\hline Variable & Superficial fat & Deep fat & P-value $^{\text {a) }}$ \\
\hline Preoperative & $230.0 \pm 50.5$ & $193.6 \pm 42.6$ & 0.436 \\
Postoperative & $170.0 \pm 68.3$ & $147.3 \pm 22.6$ & \\
Reduction rate & $25.9 \pm 26.0$ & $21.5 \pm 18.2$ & 0.813 \\
\hline
\end{tabular}

Values are presented as mean $\pm S D$. Reduction rate=(preoperative-postoperative)/preoperative 100 .

${ }^{a)}$ Wilcoxon signed-rank test.

Table 6. Body weight and fat area before and after surgery in patients with a body mass index of $40 \mathrm{~kg} / \mathrm{m}^{2}$ or more $(\mathrm{n}=6)$

\begin{tabular}{lccc}
\hline Variable & Preoperative & Postoperative & P-value ${ }^{\text {al }}$ \\
\hline Weight $(\mathrm{kg})$ & $127.3 \pm 17.7$ & $100.2 \pm 10.8$ & 0.063 \\
Total fat $\left(\mathrm{cm}^{2}\right)$ & $873.6 \pm 195.6$ & $557.0 \pm 251.7$ & 0.031 \\
Superficial fat $\left(\mathrm{cm}^{2}\right)$ & $349.8 \pm 98.7$ & $228.0 \pm 87.7$ & 0.031 \\
Deep fat $\left(\mathrm{cm}^{2}\right)$ & $311.4 \pm 107.7$ & $195.8 \pm 89.0$ & 0.031 \\
\hline
\end{tabular}

Values are presented as mean \pm SD.

${ }^{a}$ Wilcoxon signed-rank test. 
Table 7. Reduction rate in superficial fat and deep fat in patients with a body mass index of $40 \mathrm{~kg} / \mathrm{m}^{2}$ or more $(\mathrm{n}=6)$

\begin{tabular}{lccc}
\hline Variable & Superficial fat & Deep fat & P-value $^{\text {al }}$ \\
\hline Preoperative & $349.8 \pm 98.7$ & $311.4 \pm 107.7$ & 0.563 \\
Postoperative & $228.0 \pm 87.7$ & $195.8 \pm 89.0$ & \\
Reduction rate & $31.8 \pm 24.9$ & $35.8 \pm 23.7$ & 0.563
\end{tabular}

Values are presented as mean \pm SD. Reduction rate=(preoperative-postoperativel/preoperative 100 .

${ }^{a}$ Wilcoxon signed-rank test.

a significant decrease in body weight, superficial fat, and deep fat after surgery. Unlike the patients with a BMI less than $40 \mathrm{~kg} / \mathrm{m}^{2}$, the reduction rate of the deep fat was higher than that of the superficial fat, but the difference was not statistically significant (Tables 6 , 7). We also investigated the reduction rate according to sex and found no significant differences $(\mathrm{P}=0.44$ in males, $\mathrm{P}=0.56$ in females).

\section{DISCUSSION}

Skin laxity, such as an "abdominal apron", is a common problem after weight loss following by bariatric surgery. Many patients therefore need body contouring surgery, such as abdominoplasty [12]. A comprehensive knowledge of the SAT is very helpful for successful body contouring surgery.

Studies have reported the following findings regarding SAT. First, bariatric surgery reduces the volume and weight of SAT $[13,14]$. Second, metabolic and cardiovascular diseases are more closely related to visceral fat than to SAT [3]. Third, SAT is divided into two layers-deep subcutaneous adipose tissue (dSAT) and superficial subcutaneous adipose tissue (sSAT) - and each layer has different histological characteristics. Typically, in the abdomen, sSAT is thicker than dSAT and the proportion of dSAT increases with a higher BMI $[4,15]$.

Most previous studies focused only on the extent of weight loss, the resolution of metabolic diseases, and complications after bariatric surgery. Physicians and general surgeons have studied the effects of bariatric surgery on hormone levels and gene expression, but histological changes of the two-layer SAT have not been investigated $[16,17]$. Detailed research on the characteristics of the two different fat layers is still in progress and not well defined, especially in relation to surgery. The available studies were limited to only postoperative results or thickness measurements at a single time point [18-20]. In this study, we analyzed sSAT and dSAT both before and after bariatric surgery. Predictably, we found marked decreases of $29.1 \%$ in superficial fat and $29.3 \%$ in deep fat following surgery. These reduction rates were not statistically significantly different. However, when patients were divided into two groups according to whether their BMI was less than or over $40 \mathrm{~kg} / \mathrm{m}^{2}$, we found different patterns in these subgroups. In patients with a BMI less than $40 \mathrm{~kg} / \mathrm{m}^{2}$, the reduction rate of sSAT tended to be higher than that of dSAT. By contrast, in patients with a BMI over $40 \mathrm{~kg} /$ $\mathrm{m}^{2}$, the reduction rate of dSAT was higher than that of sSAT.

Adipose tissue is an endocrine organ, and when promoted by a positive caloric balance, it induces adipocyte hypertrophy, a condition known as adiposopathy [21]. In adiposopathy, adipocyte metabolism is decreased, consequently decreasing lipolysis and increasing insulin resistance [1,2]. These features of adiposopathy are more marked in dSAT than in sSAT. Deep fat is more metabolically active and is more closely associated with inflammatory gene expression and metabolic diseases, such as T2DM, than superficial fat [6-8]. Marinou et al. [22] reported that deep fat depth was a strong predictor of global insulin resistance.

Bariatric surgery results in suppressed caloric intake, decreasing body weight and subcutaneous fat mass and causing changes in gut hormones. Tissue biopsy performed before and after surgery confirmed that the decreased fat mass was caused by a decreased volume of adipocytes, not by a reduced number of adipocytes [2, $20,23]$. Because the number of adipocytes was not different, changes resulting from adipocyte hypertrophy are reversible and could be resolved through bariatric surgery. When adiposopathy is resolved through bariatric surgery, T2DM and metabolic syndrome are also resolved $[21,24,25]$. Metabolic diseases such as T2DM are associated with $\mathrm{dSAT}$, and it therefore seems that bariatric surgery is more closely associated with dSAT than with sSAT. It is expected that there will be a larger reduction of adipocyte volume in dSAT than in SSAT after bariatric surgery.

In the present study, we confirmed our hypothesis that the dSAT reduction rate was higher when bariatric surgery was performed in patients with a BMI over $40 \mathrm{~kg} / \mathrm{m}^{2}$. Although the reduction rate of sSAT tended to be higher in patients with a BMI of less than $40 \mathrm{~kg} /$ $\mathrm{m}^{2}$, this have may been because patients with mild to moderate obesity have a higher proportion of sSAT. This might reflect homeostasis, in which our body maintains a proper fat ratio balance. Thus, in patients with a relatively low BMI, interventions may focus primarily on reducing sSAT. Conversely, in patients with a BMI over $40 \mathrm{~kg} / \mathrm{m}^{2}$, a morbid state that is an indication for bariatric surgery, there is an urgent need to decrease the amount of dSAT. Therefore, it is reasonable that patients with higher BMIs have higher reduction rates of dSAT in weight loss.

The metabolically active dSAT can be modulated by bariatric surgery; therefore, plastic surgeons do not have to focus too closely on dSAT. Instead, surgeons should focus on correcting skin laxity, and paying careful attention to sSAT, which influences contour appearance, could help to achieve favorable results. We suggest that it might be better to perform abdominoplasty with sSAT-focused liposuction for patients who have undergone bariatric surgery, regardless of their BMI. In some cases, conversely, a larger amount of dSAT liposuction or dermolipectomy may be the key for achieving 
metabolic improvements.

The limitations of the present study include the following: the follow-up CT scans were not obtained at the same time in all patients, the measurements were made by only one expert, information on the patient's lifestyle during the follow-up period was not recorded, and the abdominal SAT was represented by a single-cut image. However, CT data from postoperative follow-up provide valuable information that is difficult to obtain. The current study present results from 11 patients, but it is expected that more conclusive data will be obtained from additional cases in the future. Additionally, three bariatric surgical methods were used, although consistently applying a single procedure would have produced better results.

In this study, using fat CT to compare the two layers of adipose tissue, we observed differences in the reduction rate of sSAT and dSAT after weight loss following bariatric surgery, although the differences were not statistically significant. The reduction rates differed according to BMI. In patients with a BMI over $40 \mathrm{~kg} / \mathrm{m}^{2}$, the reduction rate of dSAT was higher than that of sSAT. These results may be related to the metabolically active characteristics of deep fat and the body's homeostatic processes that maintain an appropriate fat ratio. These findings may also serve as reference data for body contouring surgery.

\section{NOTES}

\section{Conflict of interest}

No potential conflict of interest relevant to this article was reported.

\section{Ethical approval}

The study was approved by the Institutional Review Board of Dongsan Medical Center (IRB No. 2018-01-01) and performed in accordance with the principles of the Declaration of Helsinki.

\section{Patient consent}

The patients provided written informed consent for the publication and the use of their images.

\section{ORCID}

Ryeolwoo Kim

Youngsung Suh

Seungwan Ryu

Mikyung Kim

Daegu Son https://orcid.org/0000-0003-0281-9805

https://orcid.org/0000-0001-7677-2881

https://orcid.org/0000-0003-0374-5748

https://orcid.org/0000-0001-5750-3598

https://orcid.org/0000-0002-4653-1048

\section{REFERENCES}

1. Laaksonen DE, Nuutinen J, Lahtinen T, et al. Changes in abdominal subcutaneous fat water content with rapid weight loss and long-term weight maintenance in abdominally obese men and women. Int J
Obes Relat Metab Disord 2003;27:677-83.

2. Hoffstedt J, Arner E, Wahrenberg H, et al. Regional impact of adipose tissue morphology on the metabolic profile in morbid obesity. Diabetologia 2010;53:2496-503.

3. Pi-Sunyer FX. Medical hazards of obesity. Ann Intern Med 1993;119: 655-60.

4. Shin DW, Son DG, Park MS, et al. Characteristics of fat tissue according to the anatomical regions of the body: computed tomographic and histological findings. J Korean Soc Plast Reconstr Surg 2010;37:53546.

5. Lockwood TE. Superficial fascial system (SFS) of the trunk and extremities: a new concept. Plast Reconstr Surg 1991;87:1009-18.

6. Monzon JR, Basile R, Heneghan S, et al. Lipolysis in adipocytes isolated from deep and superficial subcutaneous adipose tissue. Obes Res 2002;10:266-9.

7. Walker GE, Verti B, Marzullo P, et al. Deep subcutaneous adipose tissue: a distinct abdominal adipose depot. Obesity (Silver Spring) 2007;15:1933-43.

8. Kelley DE, Thaete FL, Troost F, et al. Subdivisions of subcutaneous abdominal adipose tissue and insulin resistance. Am J Physiol Endocrinol Metab 2000;278:E941-8.

9. Walker GE, Marzullo P, Prodam F, et al. Obesity modifies expression profiles of metabolic markers in superficial and deep subcutaneous abdominal adipose tissue depots. Endocrine 2014;46:99-106.

10. Cancello R, Zulian A, Gentilini D, et al. Molecular and morphologic characterization of superficial- and deep-subcutaneous adipose tissue subdivisions in human obesity. Obesity (Silver Spring) 2013;21:256270.

11. Sugerman HJ, Wolfe LG, Sica DA, et al. Diabetes and hypertension in severe obesity and effects of gastric bypass-induced weight loss. Ann Surg 2003;237:751-8.

12. Fraccalvieri M, Datta G, Bogetti P, et al. Abdominoplasty after weight loss in morbidly obese patients: a 4-year clinical experience. Obes Surg 2007;17:1319-24.

13. Carey DG, Pliego GJ, Raymond RL. Body composition and metabolic changes following bariatric surgery: effects on fat mass, lean mass and basal metabolic rate: six months to one-year follow-up. Obes Surg 2006;16:1602-8.

14. Weiss R, Appelbaum L, Schweiger C, et al. Short-term dynamics and metabolic impact of abdominal fat depots after bariatric surgery. Diabetes Care 2009;32:1910-5.

15. Sadananthan SA, Prakash B, Leow MK, et al. Automated segmentation of visceral and subcutaneous (deep and superficial) adipose tissues in normal and overweight men. J Magn Reson Imaging 2015;41:924-34.

16. Franco JV, Ruiz PA, Palermo M, et al. A review of studies comparing three laparoscopic procedures in bariatric surgery: sleeve gastrectomy, Roux-en-Y gastric bypass and adjustable gastric banding. Obes Surg 2011;21:1458-68.

17. Tice JA, Karliner L, Walsh J, et al. Gastric banding or bypass? A systematic review comparing the two most popular bariatric procedures. 
Am J Med 2008;121:885-93.

18. Rieger UM, Raschke GF, Kalbermatten DF. Deep and superficial fat ratio in dietary and surgically induced weight loss patients. Obes Surg 2012;22:1617-22.

19. Levy S, Gomes FR, Sterodimas A. Macroscopic anatomic changes of subcutaneous fat tissue in massive-weight-loss patients. Aesthetic Plast Surg 2011;35:814-9.

20. D’Ettorre M, Gniuli D, Bracaglia R, et al. Micro- and macroscopic structural modification of subcutaneous adipose tissue after bariatric surgery. Aesthetic Plast Surg 2012;36:213-4.

21. Bays HE, Laferrere B, Dixon J, et al. Adiposopathy and bariatric surgery: is 'sick fat' a surgical disease? Int J Clin Pract 2009;63:1285-300.

22. Marinou K, Hodson L, Vasan SK, et al. Structural and functional prop- erties of deep abdominal subcutaneous adipose tissue explain its association with insulin resistance and cardiovascular risk in men. Diabetes Care 2014;37:821-9.

23. Andersson DP, Eriksson Hogling D, Thorell A, et al. Changes in subcutaneous fat cell volume and insulin sensitivity after weight loss. Diabetes Care 2014;37:1831-6.

24. Buchwald H, Estok R, Fahrbach K, et al. Weight and type 2 diabetes after bariatric surgery: systematic review and meta-analysis. Am J Med 2009;122:248-56.

25. Gloy VL, Briel M, Bhatt DL, et al. Bariatric surgery versus non-surgical treatment for obesity: a systematic review and meta-analysis of randomised controlled trials. BMJ 2013;347:f5934. 